\title{
FAT EMBOLISM SYNDROME WITHOUT OBJECTIVE EVIDENCE OF BONE OR SOFT TISSUE INJURY
}

\author{
Amitabh Das Shukla1 ${ }^{1}$ Rajneesh Kumar Srivastava², Neha Agrawal ${ }^{3}$, Ravindra Kumar Singh ${ }^{4}$
}

\section{HOW TO CITE THIS ARTICLE:}

Amitabh Das Shukla, Rajneesh Kumar Srivastava, Neha Agrawal, Ravindra Kumar Singh. "Fat Embolism Syndrome without Objective Evidence of Bone or Soft Tissue Injury". Journal of Evolution of Medical and Dental Sciences 2014; Vol. 3, Issue 52, October 13; Page: 12209-12213, D0I: 10.14260/jemds/2014/3611

\begin{abstract}
Fat embolism syndrome (FES), without evidence of bone or soft tissue injury is uncommon, and in absence of validated diagnostic criteria, its diagnosis is mainly dependent on treating clinician, who should have high index of suspicion. Treatment is predominantly supportive, and apart from some mortality, recovery is generally seen. Present article is a case report of a boy who suffered blunt injury due to fall from height, had no objective evidence of bone or soft tissue injury, but diagnosed as a case of fat embolism syndrome, using Gurd-Wilson and Schonfeld's criteria, treated by pulmonary support and aggressive resuscitation, but he died after 4 days of admission to hospital.
\end{abstract}

KEYWORDS: Fat Embolism, Bone injury, soft tissue injury.

INTRODUCTION: Fat embolism syndrome after blunt trauma has significant morbidity and mortality. It poses a significant management problem, in patients with trauma. Generally it is secondary to fracture of femur or pelvis, which dislodges marrow fat, and results in fat embolism syndrome (FES). Fracture to long bones leads to fat embolism syndrome in 0.9 to $2.2 \%$ cases. ${ }^{1}$ In lung it presents with consolidation and diffusion defect, leading to symptom of respiratory distress and hypoxemia along with radiological picture of multiple consolidation, ground glass appearance and nodularity of lung. ${ }^{2}$ Its central nervous system manifestations include confusion, drowsiness and altered sensorium. ${ }^{3}$

Some patients also present with hemiparesis and partial siezures ${ }^{4}$. Fat embolism syndrome without evidence of bone injury occurs in less than $3 \%$ cases. ${ }^{3}$ Indian experience, in congruence of Western experience, is of opinion that fat embolism syndrome is diagnosis of exclusion and high index of suspicion is required for its diagnosis.5,6 There is no specific laboratory test for its diagnosis.

Treatment is pulmonary support with aggressive resuscitation. There is almost no role of systemic corticosteroid and heparin, in established cases of fat embolism syndrome. ${ }^{1}$ We present an uncommon case of clinical significance, where a boy aged 10 years, suffered from fat embolism syndrome after fall from tree, without any objective evidence of injury to bone or soft tissue.

CASE REPORT: We hereby present a case of a boy aged 10 years, who was apparently asymptomatic, before fall from a tree. After 2 days of trauma, he started complaining of low grade fever and breathlessness, following which he reported to our hospital. On clinical examination, he was anxious, increased respiratory and heart rates, $\left(36 / \mathrm{min}\right.$ and $124 / \mathrm{min}$ respectively) body temperature $38.7^{\circ} \mathrm{C}$, no abdominal tenderness, bilateral crepts on chest auscultation and oxygen saturation on pulse oxymetry as $89 \%$. He underwent chest radiography, which revealed bilateral diffuse pulmonary infiltrates (Photo 1). 
On further evaluation by High Resolution Computerized Tomographic (HRCT) scan of thorax, there were multiple areas with nodules, ground glass opacity and consolidation of lung (Photo 2\&3). Computerized tomography (CT) of head was normal, and there was no abnormality of intracranial structures. Ultrasonography of abdomen did not reveal any site of intra-abdominal injury or bleeding. The boy was admitted in Intensive Care Unit (ICU), and was kept under observation, along with supplemental oxygen inhalation and other supportive care, but he was deteriorating rapidly, with altered mentation and oliguria as additional problem.

Lab investigations revealed raised Erythrocyte Sedimentation Rate (ESR), haemoglobin as 8 $\mathrm{g} / \mathrm{dl}$, platelet count 1.12 Lakh per micro liter, total leucocyte count 10400/microliter, with polymorph predominance, serum creatinine as $1.9 \mathrm{mg} / \mathrm{dl}$. Liver function was slightly deranged with SGPT as $56 \mathrm{IU} /$ lit but serum bilirubin was normal with value of $1.08 \mathrm{mg} / \mathrm{dl}$. Arterial Blood Gas (ABG) analysis showed Type I respiratory failure $\left(\mathrm{PaO}_{2} 56 \mathrm{~mm} \mathrm{Hg}\right)$, following which he was intubated and ventilated, along with close monitoring for $A B G$ and hemodynamic status.

Endotracheal suction revealed frothy secretions, indicating pulmonary oedema. Bed side echocardiography did not reveal cardiac failure. Applying modified Gurd'sand Wilson criteria 7,8 (Table 1) for fat embolism syndrome(FES), it was found that present case satisfied 3 major criteria and 4 minor criteria required for diagnosis. On applying Schonfeld's criteria ${ }^{9}$ (Table 2), which has more respiratory features, total scorewas 10 ( $>5$ is required for diagnosis of fat embolism syndrome). On these grounds the diagnosis of fat embolism syndrome (FES) was made and patient was managed accordingly.

While being on mechanical ventilation, he was given antibiotics, anticonvulsants, inotropic agents, oxygen supplementation, albumin infusion and other supportive management. He also underwent haemodialysis, as renal replacement therapy but he succumbed to his medical condition and died after 4 days of admission to our hospital.

DISCUSSION: The chronology of events and symptoms in present case, along with laboratory findings has been instrumental in diagnosis of fat embolism syndrome. Fat embolism syndrome, should be considered in all breathless patients, with history of trauma. ${ }^{10}$ This trauma is generally bony, but in our patient, there was no evidence of bony injury to long bones or pelvis. There were also no evidence of injury or bleeding from any intra-abdominal site. Landmark work of Gurd and Wilson ${ }^{3,11}$ provided diagnostic criteria for fat embolism syndrome, which has been subsequently modified ${ }^{7,8}$ and applied to our patient. Diagnostic criteria given by Schonfeld's had score of 10, which further supported our diagnosis. ${ }^{9}$

On application of modified Gurd and Wilson criteria, ${ }^{7,8}$ (Table 1) it was found that three major criteria of hypoxemia, central nervous system depression disproportionate to hypoxemia and pulmonary oedema, along with four minor criteria of tachycardia, pyrexia, oliguria and thrombocytopenia were present. Schonfeld's criteria (Table 2), with more respiratory features, included symptoms and signs of diffuse pulmonary infiltrates on chest radiography, tachycardia, tachypnoea, hypoxemia and fever, amounting to diagnostic score of 10 . Both these criteria are not gold standard for diagnosis of fat embolism syndrome, but since diagnosis of FES is made clinically not chemically, we arrived at diagnosis of FES, even in absence of any evidence of bony or intraabdominal injury. 


\section{Table 1: Modified Gurd and Wilson Criteria ${ }^{7,8}$}

\section{MAJOR CRITERIA:}

- Respiratory insufficiency (hypoxemia $\mathrm{PaO}_{2}<60 \mathrm{~mm} \mathrm{Hg}, \mathrm{FiO}_{2}=0.4$ ).

- Central nervous system (CNS) depression disproportionate to hypoxemia.

- Pulmonary oedema.

- Axillary or sub conjunctival petechiae.

\section{MINOR CRITERIA:}

- Tachycardia > $110 \mathrm{bpm}$.

- Pyrexia > 38.50C.

- Emboli present in the retina on fundoscopy.

- Fat globules present in urine.

- Jaundice.

- Oligoanuria.

- Sudden drop in Haemoglobin $>20 \%$.

- Sudden thrombocytopenia $>50 \%$.

- Increased Erythrocyte sedimentation rate (ESR) $>71 \mathrm{~mm} /$ hour.

- Fat Globules present in the sputum.

- Fat Macroglobinemia.

\section{Table 2: Schonfeld's Criteria9 ${ }^{9}$}

\begin{tabular}{|lll|}
\hline$\bullet$ & Petechiae & Score 5 \\
\hline - & $\begin{array}{l}\text { Chest X ray changes } \\
\text { (Diffuse alveolar infiltrates) }\end{array}$ & Score 4 \\
\hline - & Hypoxemia $(\mathrm{PaO} 2<70 \mathrm{~mm} \mathrm{Hg})$ & Score 3 \\
\hline - & Fever $(>38 \mathrm{C})$ & Score 1 \\
\hline$\bullet$ & Tachycardia $(>120 \mathrm{bpm})$ & Score 1 \\
\hline$\bullet$ & Tachypnoea $(>30 / \mathrm{min})$ & Score 1 \\
\hline
\end{tabular}

Differential diagnosis in our case, included thromboembolism, heart failure, lung contusion, pulmonary hemorrhage and fat embolism syndrome. Since characteristic non-palpable petechiae were not found over axillae and other sites as cutaneous manifestations of fat embolism syndrome, thorough examination of heart was done, to rule out thromboembolism or heart failure. Echocardiography revealed nothing, in support of right or left ventricular strain.

Treatment of our patient was predominantly supportive, and included mechanical ventilation and oxygen supplementation. Systemic corticosteroid could be of help in prevention, if used prophylactically, ${ }^{9}$ but it was of doubtful role in our case of established fat embolism syndrome. ${ }^{12}$ Prophylactic corticosteroid possibly prevents pulmonary oedema, by stabilizing pulmonary capillary membrane, blunting the inflammatory response and retarding the aggregation of platelets ${ }^{7}$. 
Although heparin has potential to clear lipemic serum ${ }^{7}$ by stimulating lipase activity, it was avoided to prevent unwanted risk of bleeding. 12

CONCLUSION: Without validated clinical criteria, diagnosis of fat embolism syndrome is quite challenging for a clinician, who should have high index of suspicion for fat embolism syndrome, particularly in breathless patients with history of trauma, even in absence of any evidence of bony or soft tissue injuries. FES is generally a self-limiting disease, with most of the patients recovering fully but, mortality of 5-15\% has been reported.7,13 Thus early diagnosis and prompt initiation of effective treatment, is essential for successful outcome.

\section{REFERENCES:}

1. Muller C, Rahn BA, P fister U, Meiniq RP. The incidence, pathogenesis, diagnosis and treatment of fat embolism. Orthop Rev 1994 Feb; 23 (2): 107-117.

2. Katerina Malagari, Nikos Economopoulos, Christophoros Stoupis, Zoe Daniil, Spyros Papiris, Nestor L. Muller. High Resolution CT Findings in Mild Pulmonary Fat Embolism. Chest 2003; 123: 1196-1201.

3. Gurd AR, Wilson RI. The Fat Embolism Syndrome. J Bone Joint Surg Br 1974; Vol 56B, 3: 408416.

4. Salazar JA, Romero F, Padilla F, Arboleda JA, Fernandez O. Neurological Manifestations of Fat Embolism Syndrome. Neurologia 1995 Feb; 10 (2): 65-69.

5. Koul PA, Ahmad F, Gurcoo SA, Khan UH, Nagash IA, Siddiq S, et al. Fat Embolism Syndrome in long bone trauma following vehicular accidents: Experience from a tertiary care hospital in North India. Lung India 2013 Apr; 30 (2): 97-102.

6. Gupta B, D'souza N, Sawhney C, Farooque K, Kumar A, Agrawal P, et al. Analyzing fat embolism syndrome in trauma patients at AIIMS Apex Trauma Centre, New Delhi, India. J Emerg Trauma Shock 2011 Jul; 4 (3): 337-341.

7. Mellor A, Soni N. Fat Embolism. Anaesthesia 2001; 56: 145-154.

8. Tzioupis CC, Giannoudis PV. Fat embolism syndrome: What have we learned over the years? Trauma 2011; 13: 259-81.

9. Schonfeld SA, Ploysongsang Y, DiLisio R, Crissman JD, Miller E, Hammerschmidt DE, et al. Ann Intern Med. 1983 Oct; 99 (4): 438-443.

10. George J, George R, Dixit R, Gupta RC, Gupta N. Fat Embolism Syndrome. Lung India 2013 Jan; 30 (1): 47-53.

11. Gurd AR. Fat Embolism: An Aid to Diagnosis. J Bone Joint Surg Br 1970 Nov; 52 (4): 732 -737.

12. Gupta A, Reilly CS. Fat embolism. Cont Edu Anaesth Crit Care Pain 2007; 7: 148-51.

13. Johnson MJ, Lucas GL. Fat embolism syndrome. Orthopedics 1996; 19: 41-48. 


\section{CASE REPORT}
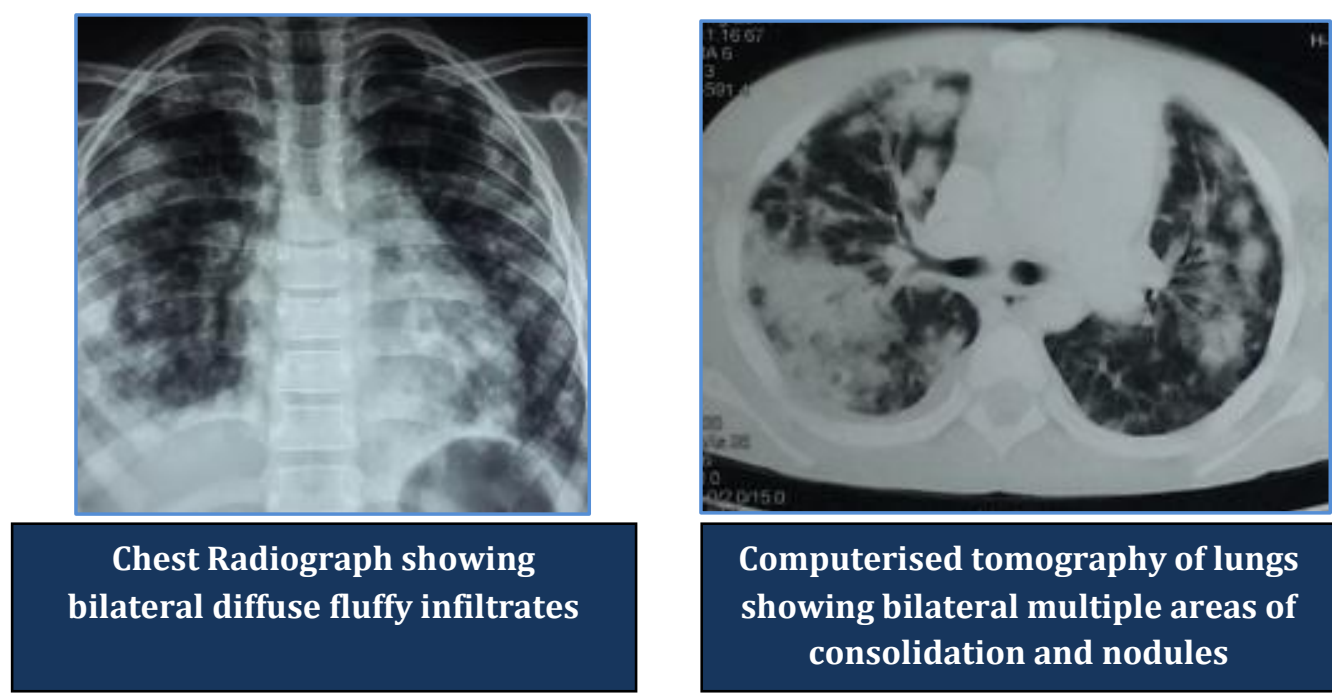

Computerised tomography of lungs

showing bilateral multiple areas of consolidation and nodules

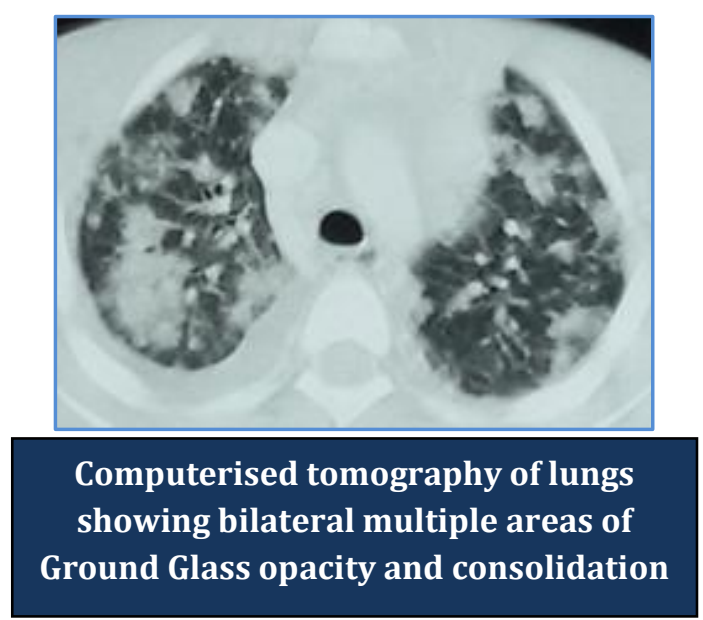

\section{AUTHORS:}

1. Amitabh Das Shukla

2. Rajneesh Kumar Srivastava

3. Neha Agrawal

4. Ravindra Kumar Singh

\section{PARTICULARS OF CONTRIBUTORS:}

1. Assistant Professor, Department of Pulmonary Medicine, MLN Medical College, Allahabad.

2. $3^{\text {rd }}$ Year Junior Resident, Department of Pulmonary Medicine, MLN Medical College, Allahabad.

3. $2^{\text {nd }}$ Year Junior Resident, Department of Pulmonary Medicine, MLN Medical College, Allahabad.
4. $2^{\text {nd }}$ Year Junior Resident, Department of Pulmonary Medicine, MLN Medical College, Allahabad.

\section{NAME ADDRESS EMAIL ID OF THE CORRESPONDING AUTHOR:}

Dr. Amitabh Das Shukla, \# 95/116A,

Amitabh Bachhan Road,

Sarvoday Nagar,

Allahpur, Allahabad-211006,

Email: adshukla1977@yahoo.com

Date of Submission: 15/09/2014.

Date of Peer Review: 16/09/2014.

Date of Acceptance: 07/10/2014.

Date of Publishing: 13/10/2014. 